\title{
Desenvolvendo um conceito de evidência histórica: as idéias dos estudantes sobre testar afirmações factuais singulares ${ }^{*}$
}

\section{Developing a concept of historical evidence: students' ideas about testing singular factual claims}

\author{
Rosalyn Ashby**
}

\begin{abstract}
RESUMO
Este trabalho discute evidências de pesquisas do Projeto Chata (Conceitos de História e Abordagens de Ensino), tendo como referência a compreensão dos alunos sobre a natureza e o status de diferentes tipos de afirmações históricas. Ele apresenta uma análise detalhada das respostas dos alunos sobre duas questões específicas, designadas para explorar aspectos do conceito de evidência histórica das crianças. Este trabalho apresenta exemplos de respostas a essas questões, com a finalidade de iluminar as idéias chave que as crianças parecem estar trabalhando no contexto desta tarefa. Um total de 320 crianças do $3^{\circ}, 6^{\circ}, 7^{\circ}$ e $9^{\circ}$ anos de três escolas primárias e seis secundárias constituem a amostra da pesquisa. Este trabalho relata a variação das idéias suscitadas na amostra dos diferentes grupos de idades, e os resultados sugerem que a maioria dos alunos dos grupos de todas as idades trata as afirmações históricas como se fossem problemas que devessem ser testados apelando-se à autoridade, ou pela identificação de uma ligação entre o principal sujeito do problema e o material que o passado deixou para trás. No entanto, os resultados também demonstram que algumas crianças foram capazes de fazer importantes distin-
\end{abstract}

* Texto traduzido do original "Developing a concept of Historical Evidence: student's ideas about testing singular factual claims" por Elizabeth Moreira dos Santos Schmidt, Luciana Braga Garcia, Maria Auxiliadora Schmidt e Tânia Braga Garcia.

** School of Arts and Humanities, University of London Institute of Education - 20 Bedford Way, London. E.mail: rosashby@lineone.net 
ções entre as afirmações feitas por declarações factuais singulares diferentes, além de trazer questões sobre o status de tais afirmações.

Palavras-chave: Educação histórica; Afirmações históricas; Fontes históricas; Evidências; Validade.

\begin{abstract}
This paper discusses research evidence from Project Chata (Concepts of History and Teaching Approaches) bearing on students' understandings of the nature and status of different kinds of historical claims. It provides a detailed analysis of pupil responses to two specific questions, designed to explore one aspect of children's concept of historical evidence. The paper provides example responses to these questions as a means of highlighting the key ideas that children appear to be working with in the context of this task. A total of 320 children from Year 3, Year 6, Year 7, and Year 9, across three primary and six secondary schools, make up the research sample. The paper relates the range of ideas apparent in the sample to the different age groups and these findings suggest that the majority of students from all age groups treat historical claims as if they were matters to be directly tested by an appeal to authority, or by identifying a link between the subject matter of the claim and material the past has left behind. However, these findings also demonstrate that some children were able to make important distinctions between the claims made by different singular factual statements, and to raise questions about the status of those claims. For these children there was a clear recognition that a test suitable for one kind of claim would not necessarily be suitable for another kind of claim.

Key-words: Historical education; Historical claims; Historical sources; Evidence; Valid.
\end{abstract}

\title{
Introdução
}

Há mais de duas décadas, Peter Rogers, em seu folheto "Nova História: Teoria na Prática", ofereceu um argumento sobre a natureza da História, a partir de uma "breve discussão das condições gerais que validavam uma afirmação de conhecimento". Ele sugeriu que, em História, quando "somos forçados a considerar as bases sobre as quais nossas afirmações de conhecimento repousam", é inadequado apelar para "uma 
boa autoridade". Apontando a futilidade da regressão infinita desta abordagem, Rogers afirma que "outras afirmações de conhecimento, além da mera autoridade, devem ser encontradas" (ROGERS, 1978, p. 4). Ele continua, dizendo:

Somente um "saber como" pode fornecer "o direito de ter certeza", porque é a única base válida para afirmações ao "saber que". Por outro lado, o "saber como" não é uma técnica geral de investigação, mas é marcado por um grande elemento específico para o tipo de área de investigação e, portanto, para o tipo de proposta para o qual foi moldado. Há diferentes tipos de evidências, que deverão ser desenvolvidas e manipuladas por diferentes estratégias de investigação (ROGERS, 1978, p. 7).

Ele complementa, sustentando que:

Há diferentes tipos de evidências que devem ser empregadas e manipuladas por diferentes estratégias de investigação, precisamente porque existem diferentes tipos de questionamentos preocupados em produzir diferentes tipos de afirmação. (ROGERS, 1978, p. 7).

Apesar de Rogers estar fazendo distinções aqui, entre diferentes estratégias de investigação em assuntos diferentes, também fica claro que diferentes tipos de questão em História demandam diferentes procedimentos de pesquisa. A História faz diferentes perguntas sobre o passado e é a natureza individual e específica dessas questões que determina o que serve como evidência na validação de qualquer afirmação de conhecimento em resposta a eles. Segue-se, também, que se diferentes questões (sobre o que aconteceu, sobre por que isso aconteceu, sobre quem é responsável pelo acontecimento, sobre o que mudou ou sobre o que era ou é significativo acerca do que aconteceu ou mudou) estão relacionadas de diferentes maneiras com a evidência, então essa relação também determina os diferentes status das afirmações feitas.

Se a investigação histórica deve estar no centro do currículo de História e ser reconhecida como um empreendimento sério nas aulas de História, então o principal para o currículo e para o empreendimento deve ser o desen- 
volvimento dos conceitos de evidência histórica pelos alunos. Rogers encorajou o uso crítico de fontes, em particular, o questionamento de testemunhos e da posição do autor para conhecer. Mas, após três décadas de "trabalho crítico com fontes", as pesquisas sugeriram que muitos estudantes possuem uma forte propensão de tratar a informação tal como ela é dada e fazer apelos às autoridades, com a finalidade de descobrir sobre o passado. Os alunos reconhecem o fato de que nosso conhecimento do passado vem de materiais do passado que foram deixados para trás; eles todos também, freqüentemente, aprendem rotinas de interrogação para lidar com fontes que pouco têm a ver com a compreensão dessas fontes enquanto evidências históricas. Enquanto os apelos às autoridades possam ser um caminho eficiente para se ganhar o acesso às particularidades históricas, e a interrogação de rotina das fontes históricas possa sustentar a sabedoria crítica de testemunhos dos alunos, sem a compreensão que Roger chama de relação simbiótica entre "saber que" e "saber como" (ROGER, 1978, p. 7), as considerações históricas continuarão conhecimento inerte, de pouco uso para a vida futura dos alunos. Eles não serão capazes de se tornar racionalmente envolvidos nos debates históricos do futuro, ou de ter qualquer esperança de compreender o motivo pelo qual as explicações sobre eventos passados ou o significado de tais eventos possam mudar ao longo de suas vidas.

A propensão dos alunos de ora apelar para autoridades para validar as afirmações históricas, ora tratar as fontes como informações de valor, ou ainda rejeitar as fontes úteis com base em um teste de segurança, era aparente no contexto do Chata (Conceitos de História e Abordagens de Ensino), pesquisa na área da Investigação Histórica, destinada a explorar a compreensão dos alunos. Um aspecto desta pesquisa examinou as abordagens dos alunos em testar as afirmações históricas, bem como seu entendimento da relação entre afirmações históricas e as evidências sobre as quais repousam. Foi pedido aos alunos que fizessem uma escolha entre diferentes afirmações históricas (que lhes foram apresentadas como breves "histórias") ${ }^{1}$ contidas na base de um conjunto de fontes (apresentadas a eles como pistas) fornecidas no contexto de informações de base relevantes, e que explicassem tal escolha. O reconhecimento da afirmação válida requeria o uso, pelos alunos, das fontes como um conjunto, além de entendê-las como evidências. Foi então pedido aos alunos que sugerissem se as fontes eram particularmente úteis (ou não), para que eles tomassem suas decisões e por quê. As fontes agiriam

1 N.T.: Utilizou-se a forma "história" correspondendo ao termo inglês story usado pela autora. 
como confirmação e clarificação do raciocínio por trás da escolhas das "histórias" pelos alunos. A análise dos dados dessas questões iniciais já foi apresentada em outros lugares e confirma a propensão dos alunos a tratarem as fontes como informações, e em considerar detalhes (como nomes, datas e números), como fatos que trazem consigo sua própria validade (LEE, ASHBY, DICKINSON, 1996; ASHBY e LEE, 1998; LEE e ASHBY, 1998; ASHBY, 2003; ASHBY, 2004). A análise dos dados também revelou o poder de uma história detalhada, expansiva, estimulante ou mais longa, sobre uma que era mais modesta e generalizada em suas afirmações e que não apresentava riscos em relação ao que poderia se afirmado com base na evidência.

Houve evidências, nesta pesquisa, que mesmo nas situações em que os alunos foram capazes de operar com conceitos sofisticados de um teste (fazendo movimentos complexos), seu tratamento das fontes como informação os levou a conclusões inválidas. Ademais, a propensão de muitos alunos em isolar particularidades nas afirmações, tratá-las como dadas e olhar somente para a informação que apoiava essas particularidades, fez com que eles ignorassem os conflitos que existiam no material, os quais só poderiam ser resolvidos se os alunos tivessem usado as fontes como um conjunto e como evidência. Nas situações em que os alunos de fato desafiaram as informações fornecidas nas fontes através do apelo às provas (tratando-as como testemunhos), ainda assim enfrentaram dificuldades para reconhecer uma afirmação válida, porque o testemunho que era rotulado como de não confiança era conseqüentemente rejeitado, ao invés de ser usado para validar outros aspectos da afirmação válida. Entretanto, o que a pesquisa também revelou foi que alguns alunos foram capazes, nas tarefas, de trazer uma compreensão sofisticada da evidência, e outros uma noção sofisticada das formas pelas quais tipos particulares de afirmações sobrevivem melhor a um teste da evidência, do que outra de maior risco. Nesse contexto, a pesquisa trouxe à tona a importância do salto conceitual que os alunos precisam fazer, e alguns foram capazes de fazer, a partir da compreensão das fontes como testemunho para trabalhar o conceito de evidência, em que as fontes têm valor reconhecido como evidência para tipos específicos de afirmações. Pode-se depreender que o ensino de História necessita prestar atenção à natureza das afirmações históricas conjuntamente aos trabalhos em que os alunos se ocupam com as fontes. Se os alunos devem desenvolver um conceito de evidência, eles necessitarão compreender a relação de evidência entre as fontes históricas (compreendidas a partir de um conceito de que foi a sociedade quem as produziu), e as afirmações sobre o passado que elas apóiam. 
O estudo também revelou as complexidades do desenvolvimento conceitual no contexto da demanda de habilidades específicas, lembrandonos que a compreensão de temas mais psicológicos e genéricos sobre o desenvolvimento cognitivo levantados pelos trabalhos de Bruner e Piaget (por exemplo, "ir além da informação dada" e centração), permanecem como aspectos importantes do conhecimento profissional do professor. Ciente de algumas dessas dificuldades e com o objetivo de vencê-las ao coletar os dados, uma série de outras questões seguiu-se à tarefa inicial. Essas foram destinadas a serem exploradas, em mais detalhes, na compreensão dos alunos sobre as fontes materiais.

\section{Compreensão dos alunos sobre as afirmações factuais singulares}

Os dados coletados em resposta a duas dessas questões é o tema deste trabalho, explorado no contexto do argumento oferecido aqui: que a investigação histórica deve permanecer como um aspecto importante da História escolar, e então desenvolver o conceito de evidência histórica nos alunos (pela exploração da natureza das questões históricas e a forma pela qual eles organizam os parâmetros para o tipo de evidência nas quais as respostas a essas questões possam estar baseadas, e na habilidade da evidência em sustentar o peso de qualquer afirmação que seja feita), deve ser o objetivo para o trabalho com fontes em sala de aula.

A amostra dessa pesquisa para os dados aqui discutidos está na tabela 1, abaixo:

TABELA 1 - FASE I - ESCOLAS

\begin{tabular}{lllllll}
\hline Escola & Fase e tipo & área & $\begin{array}{l}3^{\mathrm{a}} \\
\text { série }\end{array}$ & $\begin{array}{l}6^{\mathrm{a}} \\
\text { série }\end{array}$ & $\begin{array}{l}7^{\mathrm{a}} \\
\text { série }\end{array}$ & $\begin{array}{l}9^{\mathrm{a}} \\
\text { série }\end{array}$ \\
\hline Escola A & Primária & urbana & 17 & 29 & & \\
Escola B & Primária & cidade pequena & 16 & 18 & & \\
Escola C & Primária & rural & 22 & 28 & & \\
Escola D & Secundária compreensiva & urbana & & & 24 & 24 \\
Escola E & Secundária compreensiva & suburbana & & 24 & 25 \\
Escola F & Secundária compreensiva & urbana & & 23 & \\
Escola G & Secundária compreensiva & cidade pequena & & & 10 \\
Escola H & Secundária seletiva (garotas) & urbana + & & & 14 & 16 \\
Escola I & Secundária seletiva (garotos) & suburbana + & & & 15 & 15 \\
\hline Total & Em cada grupo de idade & & 55 & 75 & 100 & 90 \\
\hline
\end{tabular}


Idade média dos grupos: $3^{\mathrm{a}}$. série: 8 anos; $6^{\mathrm{a}}$. série, 11 anos e 2 meses; $7^{\mathrm{a}}$. série, 12 anos e 1 mês; $9^{\mathrm{a}}$. série: 14 anos e 1 mês.

A afirmação demonstrada na $1^{\text {a }}$. das duas questões era relativamente simples. Apontando para o fato de que a Pista 1 nos diz que houve uma grande batalha em Badon Hill, a questão feita era: - "Como você poderia checar se houve uma batalha em Badon Hill?"

Pista 1 - Escrita em 540 por um monge inglês chamado Gildas.

Alguns bretões foram assassinados pelos saxões, alguns foram feitos escravos. Alguns lutaram sob a liderança de Ambrosius. Às vezes, os bretões ganharam as batalhas e, às vezes, foram os saxões. Houve uma grande batalha em Badon Hill. Eu sei isso porque nasci no ano em que isso aconteceu.

A afirmação na segunda questão foi identificada de forma semelhante: "a Pista 2 nos diz que Arthur matou 960 saxões" e foi perguntado aos alunos: "Como vocês poderiam decidir se isso é verdade?".

Pista 2 - Escrita em 800 por um monge galês chamado Nennius.

O líder da guerra era chamado Arthur. Sua $12^{a}$ batalha foi em Mount Badon. Na batalha, Arthur matou 960 saxões sozinho. Ele ganhou todas as batalhas que lutou.

Esperava-se, inicialmente, que os alunos mais velhos trouxessem questões sobre o autor da fonte, ou o período de tempo no qual as fontes foram produzidas, ou, no caso da fonte 2 , porque este tipo de afirmação pode ter sido feita naquele momento. Os alunos haviam recebido material histórico auxiliar para organizar claramente o tempo, no contexto das partidas das forças Romanas e da Série de Invasões Saxônicas, bem como o gradual assentamento Saxão. No entanto, somente alguns alunos se referiram à fonte na qual a afirmação foi feita ou ao material de apoio. Os alunos aparentemente trabalharam assumindo que o local da batalha era conhecido, e somente alguns poucos contestaram a existência de Arthur no contexto da segunda questão.

A natureza da afirmação feita por esses autores era de importância considerável aqui. As perguntas, quando tomadas com um par, forneceram dados que poderiam explorar as idéias dos alunos sobre testagem no contexto de diferentes tipos de afirmação. Como os alunos tentaram resolver essas duas questões? O que contou como checagem de uma afirmação particular e em que medida os alunos conseguiram distinguir entre a natureza da afirmação que estava sendo feita na questão 1 e aquela da questão 2? Em que medida sua validação seria baseada em um apelo à autoridade, ou uma investigação sobre as posições dos autores para conhecer, ou cor- 
roboração a partir de outras fontes? As respostas foram analisadas através de um conjunto de categorias indutivas, da quais a mais firme é discutida abaixo.

\section{Decidindo se houve uma batalha em Bandon Hill}

As respostas à primeira dessas duas questões sugeriram quatro categorias principais. O gráfico I mostra a distribuição dessas respostas dentro dessas categorias, por idade, para a primeira questão. Um grande número de alunos que respondeu a essa questão queria checar esta afirmação pela autoridade dos livros e/ou especialistas, outros alunos sugeriram registros ou relíquias (principalmente corpos, ossos, armas e armaduras). Outros modificaram o uso das fontes para testar essa afirmação, sugerindo que aquelas fontes precisavam ter credibilidade para ter qualquer valor em sustentar essa afirmação, mas sem referência ao real autor dessa fonte. Alguns alunos, principalmente aqueles nos grupos dos mais velhos, questionaram a afirmação em si, no contexto da habilidade do autor para conhecer. A figura 1 mostra a porcentagem de respostas nestas categorias por grupos de idade.

FIGURA 1 - TESTANDO A AFIRMAÇÃO DE QUE HOUVE UMA BATALHA EM MOUNT BADON. PORCENTAGEM DE GRUPOS/IDADE (EXCLUINDO OS QUE NÃO RESPONDERAM)

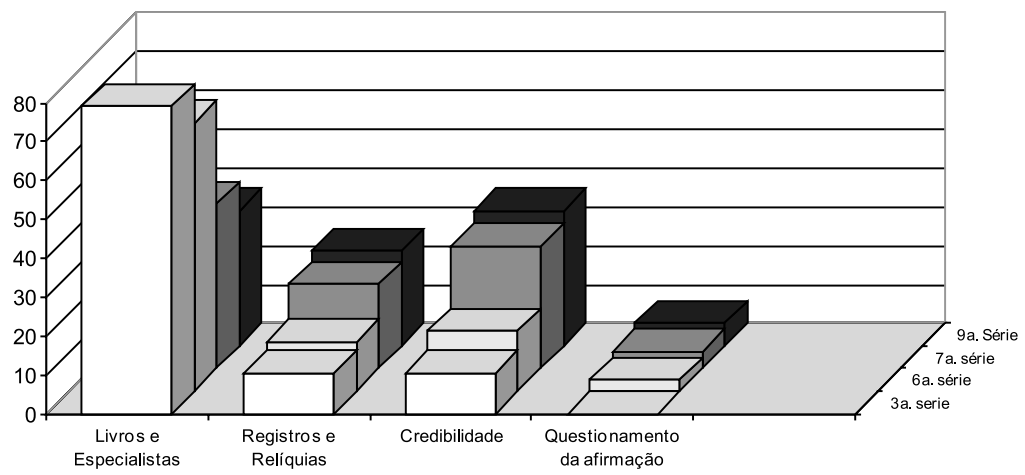




\section{Decidindo se é verdade se Arthur matou 960 saxões}

Uma categoria adicional foi sugerida por uma análise das respostas à segunda dessas questões (figura 2). Os alunos que contestaram a plausibilidade da afirmação foram identificados separadamente daqueles que questionaram a afirmação baseada na dificuldade de criar esse tipo de registro no contexto de uma batalha. Isso tornou possível identificar estudantes que reconstruíram a situação na qual foi possível produzir testemunhos e o que isso poderia significar sobre a precisão daquele testemunho. Esses alunos podem ser capazes de fazer movimentos em outros contextos históricos, que os alunos que responderam aos exageros mais óbvios dessa afirmação não são necessariamente capazes de fazer.

FIGURA 2 - TESTANDO A AFIRMAÇÃO DE QUE ARTHUR MATOU 960 HOMENS. PORCENTAGEM DE GRUPOS/IDADES/SÉRIES (EXCLUINDO OS QUE NÃO RESPONDERAM)

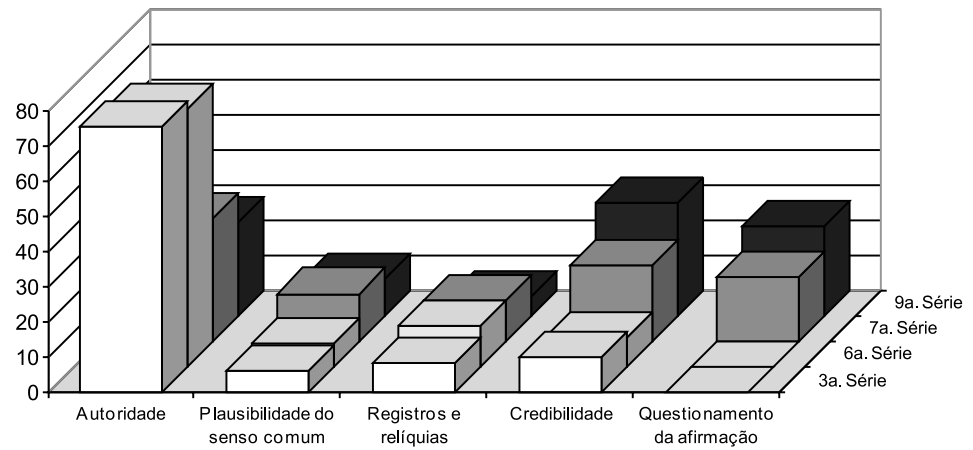

Um rápido olhar nas figuras 1 e 2 revela a propensão dos alunos nos grupos de todas as idades, mas particularmente alunos da $3^{\text {a }}$ e $6^{\text {a }}$ série, em evocar a autoridade dos livros e peritos. (Isso não é afirmar que essa não é uma forma sensível e eficiente de conhecer, mas não satisfaz o "direito de ter certeza", sugerido por Rogers, e a suposição, feita por esses alunos, é que essa informação está disponível). Dentro dessa categoria houve uma distinção entre alunos mais jovens que voltaram aos livros e professores, e alunos mais velhos que trabalharam com um sentido de especialidade, identificando livros de histórias, professores de história ou arqueólogos e museus, como fontes para validar essas afirmações. Para os alunos que queriam trabalhar a partir de fontes históricas, procurando pelos restos da guer- 
ra no campo de batalha, era um método legítimo de checar a afirmação identificada na questão 1 . Como um aluno da $7^{\text {a }}$ série sugeriu: - "nós poderíamos ir lá e cavar para ver se há alguma arma ou restos mortais", e como sugerido, esse é um movimento válido, desde que o local fosse conhecido, embora localizá-lo precisamente fosse mais difícil do que os alunos poderiam imaginar.

No entanto, nas situações em que alguns desses alunos repetem isso como método para checar a afirmação identificada na questão 2, é claro que eles não estão fazendo distinção entre os diferentes tipos de afirmações que são feitas. Respostas a essas duas tarefas (e outras tarefas da pesquisa Chata) sugerem que alguns alunos reconheceram que o material que o passado deixou para trás pode nos fornecer informações sobre o passado, mas não são capazes de fazer distinções entre o que realmente é considerado como evidência para tipos particulares de afirmações que a história faz sobre o passado ou o que não pode ser considerado. Esse tipo de movimento é claro nos dados mais amplos do Chata, em investigação histórica, no qual achados arqueológicos são compreendidos como capazes de nos contar sobre o passado, mas o acesso é direto, ao invés de inferido ou deduzido.

Considerando as duas pistas nas respostas à questão 2 (sobre como checar a afirmação que "Arthur matou 960 saxões"), segue nos quadros abaixo:

Gary (9 ${ }^{\mathrm{a}}$. série):

Olhando em outros livros de História e perguntando ao professor de História ou arqueólogo.

Alison (6 ${ }^{\text {a }}$ série):

Procurar em diferentes livros de informações e ver o que dizem. Se a maioria disser que ele matou 960 saxões, então, provavelmente, é verdade.

Laura ( $7^{\mathrm{a}}$. série):

Checando coisas que foram escavadas de Badon Hill.

Samantha ( $7^{\text {a }}$. série):

Olhando em locais ou descobrindo coisas enterradas que podem dizer algo. 


\section{Martin (9 ${ }^{\mathrm{a}}$. série):}

É difícil dizer se é verdade, porque, como saberíamos se Arthur matou exatamente 960 saxões? Será que ele estava contando quando enfiou sua espada em cada um? Assim, não acho que seja completamente verdade, acredito que ele possa ter matado muitos saxões, mas não tenho idéia como alguém possa saber exatamente quantos ele matou.

\section{Richard (9a. série):}

É muito exato para ser verdade, a não ser que alguém estivesse junto com ele para contar. Significa, provavelmente, que ele tenha executado uns 1.000 saxões após ter vencido.

\section{Lisa (9a. série):}

Eu iria checar e ver se outras fontes não tendenciosas dizem isso e decidir se era alguém tentando fazer com que Arthur parecesse maravilhoso.

Os alunos representados pelo primeiro grupo de respostas consideraram a afirmação de que Arthur matou 960 saxões como se estivessem dizendo simplesmente que "muitos saxões foram mortos". A tarefa era descobrir a resposta e o problema estava limitado em relação a onde você iria procurar, e o que você iria procurar. Então, Alison e Gary nos levaram às autoridades, e Laura e Samantha ao local presumido. Gary queria perguntar a um especialista ou olhar em livros de História. Laura e Samantha, ao que foi encontrado. As demandas particulares da afirmação simplesmente não foram direcionadas.

As dificuldades que permaneceram intocadas por tais movimentos são esclarecidas por outro aluno, David, 7a. série, que escreveu: "Você poderia ir a Badon Hill e procurar por ossos. Se você encontrar muitos ossos, aí você poderia saber. Mas você jamais saberia se ele matou exatamente 960 saxões". É possível, é claro, que ele veja o problema como o simples trabalho prático de encontrar os ossos para realizar o trabalho de contagem de maneira acurada, mas essa resposta pode reconhecer que uma afirmação como essa levanta outras dificuldades, além de meros números.

Os alunos no segundo grupo de respostas começaram a ver que existem pontos complexos envolvidos na checagem de uma afirmação desse tipo. Martin, $9^{\mathrm{a}}$, série, ao se defrontar com problemas levantados pelo núme- 
ro exato, reconheceu como seria difícil atribuir isso às ações de uma pessoa em particular e nessa circunstância específica. Richard, $9^{a}$ série, também observou dificuldades de contagem e trouxe a possibilidade de como uma situação mais formal pode ter tornado isso possível, ainda que querendo ficar distante da exatidão do número, preferindo arredondar para 1000 .

Lisa ( $9^{\mathrm{a}}$ série), entretanto, foi além do problema dos números e, tecendo considerações sobre porque alguém poderia querer fazer tal afirmação, levantou questões sobre o tipo de afirmação que estava sendo feita. A própria afirmação sugere tendências por parte do autor e atribui um objetivo particular a ele, por querer "fazer Arthur parecer maravilhoso". A estratégia de Lisa de checar outras fontes não tendenciosas pode não servir também, já que as tendências que ela estava reconhecendo estavam incutidas na própria afirmação, e ela não lidou com isso no contexto daquele tempo.

Uma discussão das respostas dos alunos dentro das quatro categorias principais esclarece o tipo de pensamento que os professores precisam contestar ou encorajar, para sustentar ou auxiliar o progresso de seus alunos, para que estes possam lidar com as complexidades das evidências históricas em relação às afirmações históricas.

\section{Livros e Especialistas}

Os alunos, nesta categoria, estavam preocupados em olhar alguma autoridade para obter confiança sobre a verdade das afirmações que eles receberam. Alguns queriam olhar em livros ou perguntar a alguém, embora estivessem procurando uma resposta conhecida ou pré-existente para a questão. Outros reconheceram que a informação era complexa e que apareceram dificuldades para, realmente, achar as autoridades. Houve reconhecimento que o conhecimento era especializado e, assim, fontes de conhecimento eram freqüentemente organizadas para acomodar sua pesquisa. Um índice, ou uma enciclopédia, a estante de História da Biblioteca ou o Museu, auxiliam uma pesquisa com o objetivo de se obter alguma autoridade letrada para o problema. As pessoas também se especializam: professores de História, historiadores, arqueólogos, poderiam fornecer a informa- 
ção necessária para checar essa afirmação. Alguns eram amedrontados pela segunda afirmação, e Emma ( $6^{\mathrm{a}}$ série), escreveu: "Bem, eu poderia procurar, mas espero que não seja verdadeiro".

Dentro dessa categoria, houve outras distinções que poderiam ser feitas, e havia um sentido de que precisavam ter algum cuidado, mesmo com as autoridades desse tipo. Alguns alunos queriam pegar "vários livros" ou "perguntar a diferentes historiadores". Procurar por concordância, ou pelo que a maioria dos livros dizia, era uma forma importante de checar a informação encontrada em qualquer livro em particular, ou a informação dada por uma pessoa específica. Como Peter ( $7^{\text {a }}$ série), sugeriu: "Você pega toneladas de informações e vê qual parte é a mais popular". Contar as fontes de informação como ponto corroborativo para validar afirmações (feitas pelas histórias e pistas), era uma abordagem freqüentemente realizada pelos alunos.

\section{Relíquias e registros}

Essa categoria registrou respostas daqueles alunos que reconheceram que as afirmações históricas marcaram algumas relações com o que o passado deixou para trás, mas viam isso como uma conexão direta. Se você quisesse saber se houve uma Batalha em Badon Hill, você simplesmente iria ao local e lá encontraria as armas e restos mortais. A questão se o local era conhecido não foi levantada e pouca inferência foi necessária por parte dos alunos. Isso poderia funcionar bem para a questão 1 , se a existência do local fosse admitida, mas não seria, é claro, apropriada para a questão 2 . As respostas dos alunos que foram agrupadas nessa categoria na pergunta 1 não caíram na mesma categoria na questão 2 , como mostram as figuras 1 e 2. Entretanto, alguns que quiseram procurar por armas e restos mortais para a primeira questão, procuraram suas respostas para a segunda questão da mesma forma. Laura e Samanta (no primeiro grupo dos exemplos discutidos acima), eram alunas típicas que não fizeram distinções sobre o tipo de afirmações que estavam checando, mas reconheceram que a checagem em afirmações sobre o passado deveria atender ao que o passado deixou para trás. No entanto, muitas respostas nessa categoria tende- 
ram a ter abordagem "tópica" à informação que era necessária ser encontrada, e as distinções entre os alunos foram possíveis no contexto das duas questões.

\section{Credibilidade}

Essa categoria registrou respostas que olharam para o que o passado deixou para trás, para validar as afirmações, e, adicionalmente, aceitaram que estas fontes tivessem alguma credibilidade. As respostas dos alunos podem ser colocadas em três grupos amplos.

Primeiro, fontes primárias tinham créditos se concordassem com outras fontes. Isso funcionou muito da mesma forma como ao pesquisar concordância na categoria de Livros e Especialistas. Mas, aqui, os alunos queriam checar com fontes que, de alguma forma, fossem atreladas ao passado. Richard ( $7^{\mathrm{a}}$ série), sugeriu "uma pesquisa com muitas pistas e com uma média acima de $80 \%$, que seria suficiente para dizer que as opiniões eram verdadeiras." $\mathrm{O}$ consenso era obviamente uma checagem importante em qualquer informação, e esta abordagem numérica para validar as afirmações é característica das respostas de vários alunos, sobre uma gama tarefas de pesquisa.

Outras respostas sobre os tipos de fontes necessárias foram mais explícitas, e "fontes de época" foram freqüentemente vistas como as de maior credibilidade. No entanto, essas fontes que são referidas como "de época" parecem estar sendo usadas como testemunhas oculares, esteja ou não a fonte de época afirmando ser testemunha do evento que está descrevendo. Há uma grande evidência a partir dos dados, sugerindo que os alunos que usaram "de época", o fizeram com precisão limitada sobre o que uma "fonte de época" é capaz de sustentar.

Um terceiro e pequeno grupo, nessa categoria, procurou a credibilidade do autor de uma fonte. Caroline ( $9^{\mathrm{a}}$ série), em resposta à questão 2, afirmou que "Escritos dos monges deveriam ser particularmente úteis pois estes supostamente eram inteligentes e deveriam ter escrito os fatos, ao invés de elaborá-los ou mentir sobre o evento. 
Nesta categoria, para respostas à questão 2, a natureza da afirmação não foi levantada: não houve dificuldades especiais envolvidas na validação de tal afirmação. Apesar de uma distinção ter sido feita entre precisar de armas e restos mortais, para checar a afirmação da questão 1, e a necessidade de testemunhas oculares para a questão 2, continuou sendo considerado que uma ou várias testemunhas oculares era tudo o que eles precisavam. Ademais, o fato de que os monges não mentem foi suficiente para dar credibilidade ao autor da fonte 2 .

\section{Questionando a afirmação}

As respostas nesta categoria foram além de apenas obter a informação, procurar por concordância ou acesso a relíquias ou informações dos testemunhos oculares. Eles demonstraram conhecimento de que as inferências poderiam ser feitas a partir das fontes, que você pode ser capaz de "trabalhar as coisas" a partir das fontes, e que em algum sentido as fontes poderiam fornecer evidências. Outros reconheceram o problema de que tipos particulares de fontes não tornariam possível, necessariamente, fazer certas afirmações, principalmente devido à natureza de tais afirmações. Martin e Richard, ambos da $9^{a}$ série (ver o quadro acima), exemplificaram este tipo de resposta em suas respostas à questão 2. Como Martin e Richard, alguns alunos reconheceram que o tipo de afirmação feita na questão 2 levantou questões sobre por que alguém poderia fazê-la e como poderia fazê-la aparecer. Todos foram além da pesquisa sobre a informação como dada ou como fato reconhecido que pode ser acessado se você for à fonte correta. Eles reconheceram as limitações ou foram além de simples concordância com os testemunhos oculares. Eles ofereceram um mecanismo que permitiu examinar a afirmação a ser feita, no contexto de como você deve ser capaz de conhecer, e os problemas que podem surgir no caminho do conhecimento, ou questionar, de alguma forma, como a própria afirmação apareceria. Olhar os testemunhos a partir das circunstâncias em que foram produzidos é um aspecto importante da compreensão dos alunos sobre a natureza das fontes históricas e, portanto, das afirmações que poderiam ser feitas baseadas nos fatos citados. 


\section{Plausibilidade}

A figura 2 demonstra uma categoria adicional àquelas utilizadas na figura 1, de "um senso-comum de plausibilidade". Alguns alunos julgaram a afirmação específica da 2 inacreditável. Para alguns deles, o problema foi trabalhado com um apelo à experiência humana: não era fisicamente possível para um ser humano fazer isso, apesar de um aluno da $6^{\mathrm{a}}$ série, na fase de testagem dessa pesquisa, ter sugerido que, se fosse verdade que Arthur tinha uma espada mágica, então seria possível ter matado todos aqueles Saxões sozinho. Essa abordagem da plausibilidade do senso comum foi claramente expressada por Robert ( $9^{a}$ série), que escreveu: "Eu não posso acreditar que um homem pudesse matar 960 saxões de uma vez, é quase fisicamente impossível". Michael, $7^{\mathrm{a}}$ série, não acreditou também: "Eu não faria isso. Eu não acredito em tudo que ouço e matar 960 saxões é horrível. Alguém, provavelmente, fez isso por ele". Presumivelmente, ele quis dizer que Arthur teve ajuda. Essa categoria representa um tipo importante e resposta a outros tipos de afirmações que podem ser encontradas em História. A forma pela qual os alunos recriam as situações cotidianas pelas quais examinam a possibilidade de ação ou prática no passado particular é provavelmente reconhecida por muitos professores e tem alguns procedimentos importantes na compreensão de suas idéias sobre evidência e empatia. Isso pode indicar os primeiros passos na criação daquilo que Wineburg chama "situação modelo". (WINEBURG, 1994).

As figuras 1 e 2 apontam a porcentagem de respostas de cada grupo de idade em diferentes categorias descritas e exemplificadas acima e sugerem que:

- No contexto de ambas questões os alunos mais jovens tendem a contar com a autoridade de livros e especialistas, mais do que os alunos mais velhos, ainda que permaneça um número de alunos mais velhos que também o fazem;

- Há uma diferença significativa entre as respostas dos dois grupos de escolas primárias e as dos grupos das duas escolas secundárias em apelar para a autoridade dos livros e peritos, com pequena diferença entre os dois grupos das escolas primárias e dos dois grupos das secundárias;

- Os alunos mais velhos tendem a questionar a credibilidade das fontes mais do que os mais jovens, e, novamente, as respostas demonstram uma diferença significativa entre grupos das escolas primárias e secundárias. 
Um exame das diferenças chave entre as figuras 1 e 2 sugere que:

- O grupo da escola secundária tende a fazer distinções na natureza das afirmações que estão sendo testadas, mais do que o grupo das escolas primárias, reconhecendo que, ainda que seja possível testar a probabilidade de uma batalha em um lugar específico escavando para procurar relíquias neste local, essa abordagem não tende a produzir evidência de quem matou ou de quantos foram mortos por uma pessoa em particular.

- A natureza da afirmação testada na questão 2 encorajou os alunos da $7^{\mathrm{a}}$ e $9^{\mathrm{a}}$ séries a questionarem a afirmação que estava sendo feita, mas não teve tal impacto na $3^{\mathrm{a}}$ e $6^{\mathrm{a}}$ séries.

\section{Conclusões/Implicações}

Há, é claro, muita discussão entre professores e professores educadores sobre o que é chamado de "boa prática" e "má prática", mas isso não deve ser uma divisão entre a situação do passado e do presente no ensino de História. "Boa" e "má" prática são quase sempre identificadas, independentemente dos objetivos que o professor tenha em mente. Esses objetivos parecem ter sido deslocados do ensino e da avaliação da compreensão conceitual da evidência, da "fonte de trabalho" que, em muitas formas de trabalhar e sistemas de avaliação, parece não ir além da rotina de reunir e descobrir, gradualmente, a informação, ou de demonstrar que se você usar um conjunto de fontes, você terá uma interpretação e, se você usar outro conjunto, você produz uma outra interpretação competitiva. É o objetivo dos professores que determina a natureza do trabalho com as fontes históricas na sala de aula, bem como esclarece práticas diferentes do passado e do presente. Pode ser que as discussões sobre o objetivo do trabalho com as fontes na escola e sua relação com as afirmações ou interpretações históricas sejam mais proveitosas do que meras discussões sobre fontes e sua extensão.

Se um desses objetivos é desenvolver a compreensão da evidência, pelo aluno, o principal obstáculo a essa persistência é tratar o trabalho com fontes como uma atividade baseada em tarefas. Além disso, geralmente, as palavras "evidência" e "fonte" são usadas como recíprocas, e tanto professores como alunos devem fazer claras distinções aqui. É particularmente 
preocupante quando, na tentativa de ajudar os estudantes, os professores utilizam materiais comercialmente produzidos na sala de aula que reforçam as noções equivocadas que os alunos possam ter. (Eu tenho em mente aqui um pôster comercialmente produzido, demonstrando "Reis da Evidência", quando o que realmente significa é "Rei das Fontes"). Se se quer fazer progresso com os alunos, eles precisam entender que as fontes não são a mesma coisa que evidência, e é preciso desenvolver uma compreensão conceitual da relação de evidência entre fontes e afirmações. A "relação simbólica" que Roger identifica, deve ser encorajada na sala de aula, mas também deve levar os alunos além das fontes correspondentes para afirmações no nível da informação, ou o levantamento de fontes para determinar a validade de afirmações particulares.

Pensando historicamente sobre as duas décadas passadas, Denis Shemilt, em seu Estudo Avaliativo sobre o SHP, apontou que:

As crianças podem começar a lidar com lacunas, contradições e tendências em fontes, mas, até que consigam raciocinar hipoteticamente, elas insistem em esperar que a evidência, por meios misteriosos, quase que literalmente lhes diga o que aconteceu. Somente quando a criança consegue hipotetizar, ela pode claramente predizer o que algum pedaço de evidência deve ou não, apropriadamente, revelar; somente aí ela pode dizer que evidências adicionais podem ser necessárias e especular onde podem ser encontradas. (SHEMILT, 1980, p. 47).

Neste momento, foi particularmente recompensador e estimulante para os professores o fato que o estudo de Denis Shemilt apontou: "Apesar da dificuldade intelectual desse processo, um grande número de candidatos do Projeto foi capaz de resolver problemas históricos ao formar e testar hipóteses" (SHEMILT, 1980, p. 47).

A pesquisa revela a sofisticação do pensamento de muitos alunos em relação à história e a pesquisa Chata atesta a complexidade de compreensão que alguns alunos têm sobre a natureza da História. Para encorajar mais alunos a pensarem dessa forma sofisticada, provavelmente seja importante lembrar as palavras de Shemilt em 1980 e como essas palavras devem nos ajudar a superar os limites atuais: 
A capacidade de raciocinar em termos proporcionais é necessária antes que qualquer um possa compreender que a História não é - e não pode aspirar a conduzir a - uma verdadeira pintura sobre o passado (mesmo porque não há um original contra o qual a ocorrência desta pintura possa ser checada). A História tenta nada além do que fazer afirmações sobre o passado, válidas em termos de evidências disponíveis. Mas uma criança incapaz de raciocinar proposicionalmente não pode compreender a diferença entre uma afirmação verdadeira e válida, uma representação acurada e justificada do passado. (SHEMILT, 1980, p. 47).

\section{REFERÊNCIAS}

ASHBY, R. O conceito de evidência histórica: exigências curriculares e concepções de alunos. In: BARCA, I. (Ed.). Educação histórica e museus. Braga: Centro de Investigação em Educação, Universidade do Minho, 2003.

. Students' approaches to validating historical claims. In ; GORDON, P.; LEE, P. (Eds.). International review of history education v. 4: understanding history research in history education. London: Routledge, 2004. No Prelo.

.; LEE, P. Children's ideas about the testing of historical claims and of the status of historical accounts. New York: Research paper given at AERA, 1996. 1998.

. Information, opinion and beyond. San Diego: Research paper given at AERA,

BRADLEY, F. H. The presuppositions of critical history. Chicago: Quadrangle, 1968.

BRUNER, J. S. Beyond the information given: studies in the psychology of knowing. London: George Allen and Unwin, 1974.

LEE, P. J.; ASHBY, R. Discussing the evidence. In: Teaching history, 48. London: Historical Association, 1987. 1998.

. History in an information culture. San Diego: Research paper given at AERA,

;) DICKINSON, A. K. Progression in children's ideas about history. In: HUGHES, M. (Ed.). Progression in learning. Clevedon: Multilingual Matters, BERA Dialogues II, 1996.

ROGERS, P. J. The new history: theory into practice. London: The Historical Association, 1978. Issue n. 44. 
SHEMILT, D. Evaluation study. Edinburgh: Holmes McDougall, 1980.

WINEBURG, S. Contextualized thinking in history. In: CARRETERO, M.; VOSS, J. F. (Eds.). Cognitive and instructional processes in history and the social sciences. Hillsdale: Lawrence Erlbaum Associates, 1994.

Texto recebido em 16 fev. 2005 Texto aprovado em 17 nov. 2005 